\title{
Congenital nephrotic syndrome and renal vein thrombosis in infancy
}

\author{
F. ALEXANDER ${ }^{1}$ AND W. A. B. CAMPBELL
}

From the Institute of Pathology, Queen's University of Belfast

SYNOPSIS Three of the four cases of the nephrotic syndrome in infancy described show the typical clinical and pathological features of the commonly termed congenital nephrotic syndrome, and two of them abnormal immunoglobulins. Two of the infants were siblings. The placental abnormalities and renal electron microscopic changes are reported and are believed to be involved in antigenantibody reactions. The literature is reviewed and the possible aetiology of these lesions is discussed. The fourth case is considered to be due to thrombosis of the inferior vena cava and renal veins, an extremely rare cause of the nephrotic syndrome in infants.

The nephrotic syndrome, occurring at or soon after birth, is generally referred to as the congenital nephrotic syndrome. It is considered to be an inherited disease in Finland, where at least 66 families with 85 cases are known (Norio, 1966). Outside Finland, however, there are very few reports of this condition in siblings (Giles, Pugh, Darmady, Stranack, and Woolf, 1957; Kendall-Smith, Pullon, and Tomlinson, 1968). The underlying aetiology remains obscure and has been considered variable. Three infants with the nephrotic syndrome, including two siblings, have recently been seen at the Royal Belfast Hospital for Sick Children and are recorded with a fourth case, drawn from the files of the Pathology Department, the Johns Hopkins Hospital. The placenta, only once described in this condition (Kouvalainen, Hjelt, and Hallman, 1962) was available for study in one infant.

Renal vein thrombosis in infancy is uncommon and its association with the nephrotic syndrome in this age group is distinctly rare. Only three previous cases have been recorded (Fetterman and Feldman, 1960; Torres, 1962; Roy, Bedard, Bonenfant, and Fortin, 1964). A fourth case has been reported in an 18-month-old child (Feinerman, Burke, and Bahn, 1957). It is remarkable, therefore, that although not the primary disease process in two, three of the four infants described here showed varying degrees of thrombus formation, from occlusion of the inferior vena cava and both renal veins to glomerular capillary fibrin thrombi. No acute episode of diarrhoea, vomiting, dehydration, pal-

Received for publication 2 July 1970.

'Present address: Department of Pathology, Foothills Hospital, Calgary, Alberta, Canada. pable flank mass, or haematuria, such as one usually finds with renal vein thrombosis in infants, was observed.

\section{Case 1 (J.B. A19692)}

This infant was born on 15 January 1963, after a normal delivery, and weighed $3,550 \mathrm{~g}$. The placenta was noted to be 'massive and elongated' and the mother had a postpartum haemorrhage. A large piece of placental tissue was removed manually and part of this was sent for histological examination. The baby, though apparently well at first, was observed to have abdominal distension on 21 January. She did not gain weight properly and developed cyanosis of the lips after feeding. The family doctor noticed oedema of the back, feet, and legs when called to see the baby, then aged 4 weeks, with a 'head cold'. She was first treated with antibiotics and admitted to the Royal Belfast Hospital for Sick Children for investigation on 19 February. On examination she was puffy looking and anxious with generalized oedema. The family history was negative for renal disease and four siblings were alive and well.

On admission the relevant laboratory findings were: haemoglobin $10.5 \mathrm{~g} / 100 \mathrm{ml}$ (Haldane); cholesterol $310 \mathrm{mg} / 100 \mathrm{ml}$; blood urea was $38 \mathrm{mg} /$ $100 \mathrm{ml}$; total plasma protein $4.4 \mathrm{~g}$ (albumin $0.95 \mathrm{~g}$, $\alpha_{2}$ globulin $1.27 \mathrm{~g}, \gamma$ globulin $0.99 \mathrm{~g}$ ); 24-hour urine volume $120 \mathrm{ml}$ (protein $550 \mathrm{mg} / 100 \mathrm{ml}$ and occasional pus cells and red cells present but no significant growth of organisms). The haemoglobin fell to $8.9 \mathrm{~g} / 100 \mathrm{ml}$, and the ESR (Wintrobe) was $60 \mathrm{~mm} /$ hour. Total proteins fell to $2 \cdot 7 \mathrm{~g}$ on $8 \mathrm{March}$ (albumin 
$0.6 \mathrm{~g}, \alpha_{2}$ globulin $0.94 \mathrm{~g}, \gamma$ globulin $0.38 \mathrm{~g}$ ), and blood urea rose to $65 \mathrm{mg} / 100 \mathrm{ml}$. The urine remained sterile on 19 March and a specimen on 13 April showed generalized aminoaciduria.

The nephrotic syndrome was diagnosed and treatment with prednisone $1 \mathrm{mg} / \mathrm{lb}$ body weight/day was given with penicillin supportive treatment. No response was observed and the dose of prednisone was increased. Abdominal distension with ascites developed and the infant died on 22 March aged 9 weeks.

\section{EXAMINATION OF PLACENTA}

The portion of placenta received weighed $175 \mathrm{~g}$. The total weight of the placenta was not stated. Histological examination showed areas of villi which would be accepted as normal but in adjacent areas villi were distinctly hydropic. The stroma was oedematous. The Langhans layer remained in patches (Fig. 1), and there were occasional syncytial knots. The blood vessels were often prominent, though in some villi they appeared to be decreased

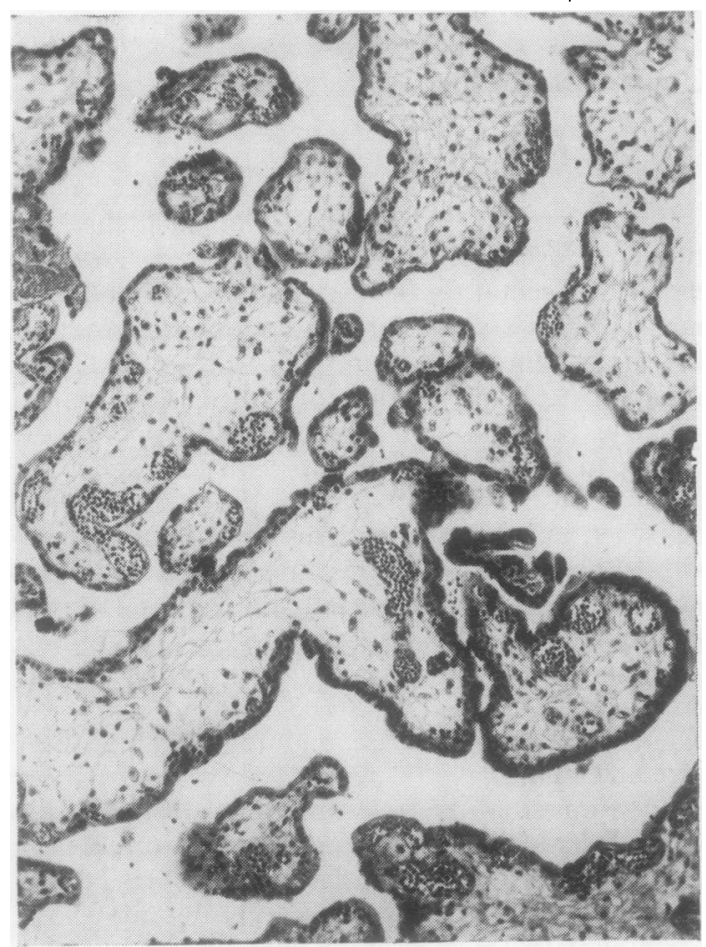

Fig. 1 Oedematous villi with persistence of Langhans layer. Blood vessels varied from abundant and central to sparse and peripheral. $H$ and $E \times 120$. in number and size. They were occasionally centrally placed but elsewhere appeared more mature and tended to lie towards the surface of the villi. There was no excess of nucleated red cells in the foetal channels. Fibrin was deposited between villi but not in excess. Very occasionally in a villus a little calcium deposit was seen in the basement membrane deep to the syncytium.

\section{NECROPSY FINDINGS}

At necropsy generalized pitting ozdema was present and the abdomen was markedly distended. Approximately $100 \mathrm{ml}$ of clear fluid was obtained from each pleural cavity and $500 \mathrm{ml}$ from the peritoneal cavity. No lesion was found in the heart or lungs, apart from focal atelectasis, congestion and oedema. No pulmonary emboli were seen. The main pathological findings were confined to the kidneys which were markedly swollen. The capsule stripped easily to leave a lobulated surface but no scars. The cortex appeared more swollen than the medulla with a corticomedullary ratio of $1: 2$. No pelvi-ureteric

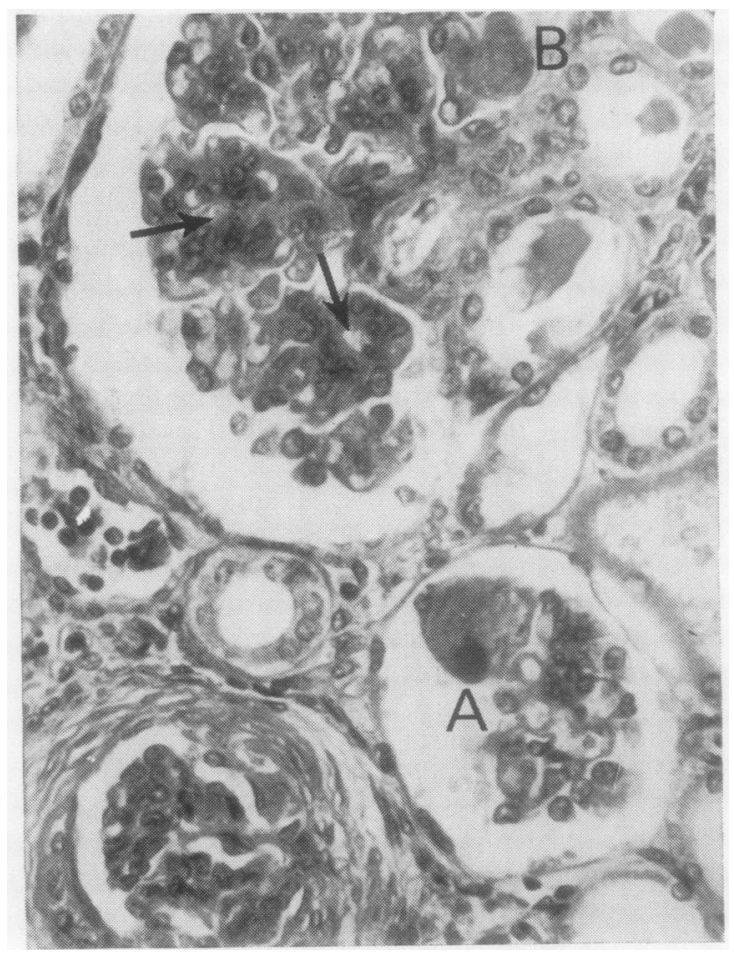

Fig. 2 Mesangial hypercellularity ( $\downarrow$ ), capsular adhesions and periglomerular fibrosis are evident. Fibrin is present in capillary loops $(A$ and $B) . H$ and $E \times 420$. 
abnormality was noted. Both renal veins were occluded by organizing thrombi.

Histological examination revealed an early acute bronchopneumonia. The renal and adrenal veins were occluded by organized thrombi. The main histological lesion was observed in the kidneys. The most striking superficial feature was the patchy, unequal tubular dilatation most marked in the inner cortex and not involving the medulla to any significant degree. The tubules contained varying quantities of pink amorphous material and occasionally cellular debris. Strikingly in many areas dilatation of the macula densa region of the distal tubule could be observed, the limbs of Henle were not dilated, and in the absence of involvement of medullary tubules the lesion appeared to be only in the convoluted tubules. The lining epithelium was cuboidal or flattened and no necrosis was observed. The glomeruli varied in size. The smaller, more compact and often superficial glomeruli retained a prominent superficial layer of cuboidal epithelial cells. The larger open glomeruli contained areas of

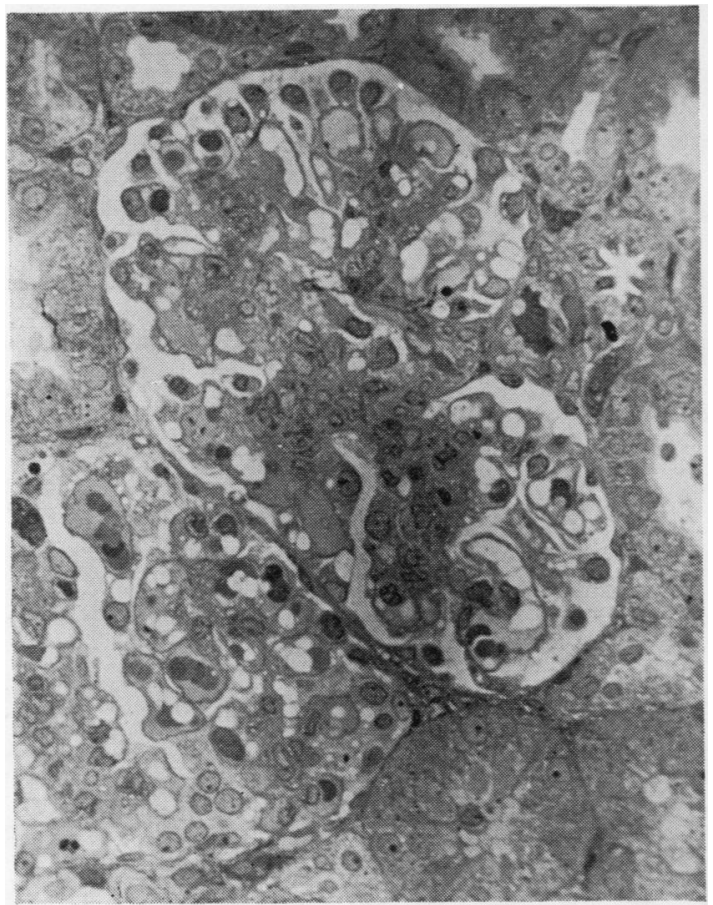

Fig. 3 Mesangial hypercellularity is marked and vacuoles are present in epithelial and possibly endothelial cells. Toluidine blue $\times 500$. mesangial hypercellularity. Epithelial crescent formation, capsular adhesions, and periglomerular fibrosis were observed, though not widespread (Fig. 2). The suspicion of rare fibrin thrombi in capillary loops was confirmed by the PTAH stain. Slight capillary basement membrane thickening was suggested with PAS and methanamine silver stains. A mild increase in oedematous interstitial tissue was noted with little increase in inflammatory cell infiltrate. The small blood vessels were often hyperplastic. Two microscopic foci of immature mesenchyme and abnormal tubules were observed. The renal vein and its major branches contained organizing and recanalized thrombi. The pelvis was not inflamed.

\section{Case 2 (A.B. A25929)}

This baby, a sibling of case 1 , was born on 13 January 1968. The birth weight was $3,267 \mathrm{~g}$. The placenta was large, oedematous, and unhealthy looking, weighing $2,073 \mathrm{~g}$. On discharge of the

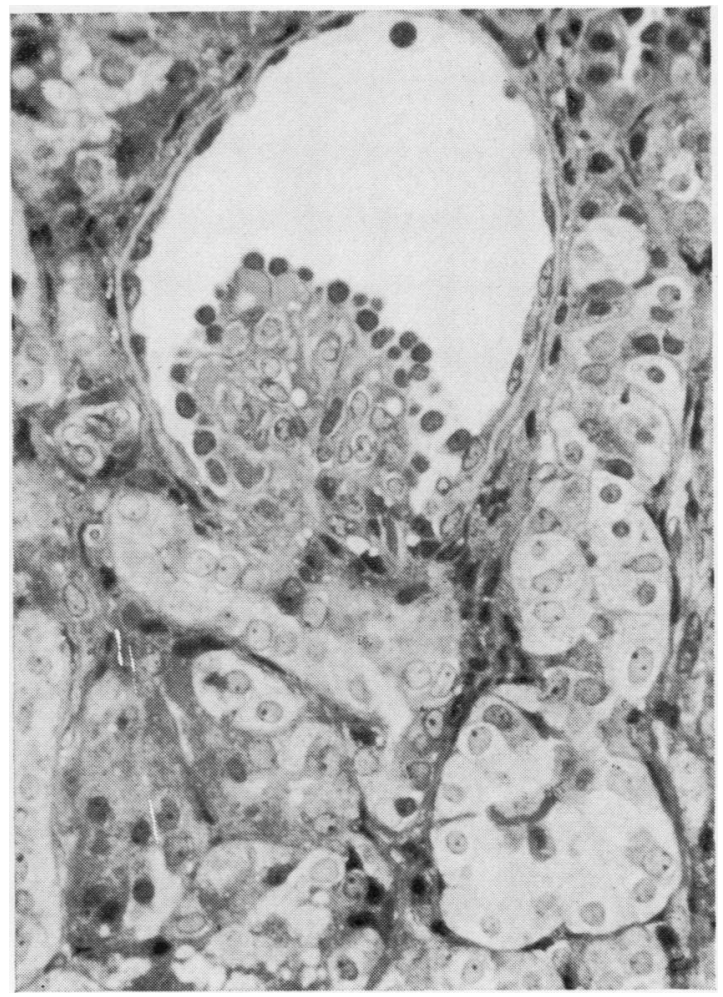

Fig. 4 The glomerular tuft is small with a prominent layer of epithelial cells. Bowman's space is dilated. Toluidine blue $\times 500$. 
mother, one week after delivery, the baby was kept for observation because of cyanosis and limpness after feeding. At the age of 8 days the legs were oedematous and marked puffiness of the eyes was noticed by the mother at three weeks. He was admitted to the Royal Maternity Hospital, Belfast, on 9 February 1968 when he weighed 4,545 g. There was massive generalized oedema. Blood pressure was $130 / 95 \mathrm{~mm} \mathrm{Hg}$. Urine showed albuminuria ++++ .

Laboratory investigations gave total plasma proteins $3.4 \mathrm{~g} / 100 \mathrm{ml}$ (albumin $1.3 \mathrm{~g} / 100 \mathrm{ml}$ and $\alpha_{2}$ globulin $1.1 \mathrm{~g} / 100 \mathrm{ml}$ ); serum cholesterol 212 $\mathrm{mg} / 100 \mathrm{ml}$. Urine culture was negative. The antistreptolysin -0 titre was $<166$ units and C-reactive protein was negative. An intravenous pyelogram on 19 February was normal. Two weeks later the haemoglobin had fallen to $9.6 \mathrm{~g} / 100 \mathrm{ml}$ and the leucocyte count was $12,400 \mathrm{cmm}$. A urinary tract infection was diagnosed. He was treated with an assortment of antibiotics. A high-protein, low-salt diet and corticosteroids temporarily raised the total proteins and reduced the oedema. Protein loss in the urine remained high at $4 \cdot 1 \mathrm{~g} / 24$ hours in $120 \mathrm{ml}$

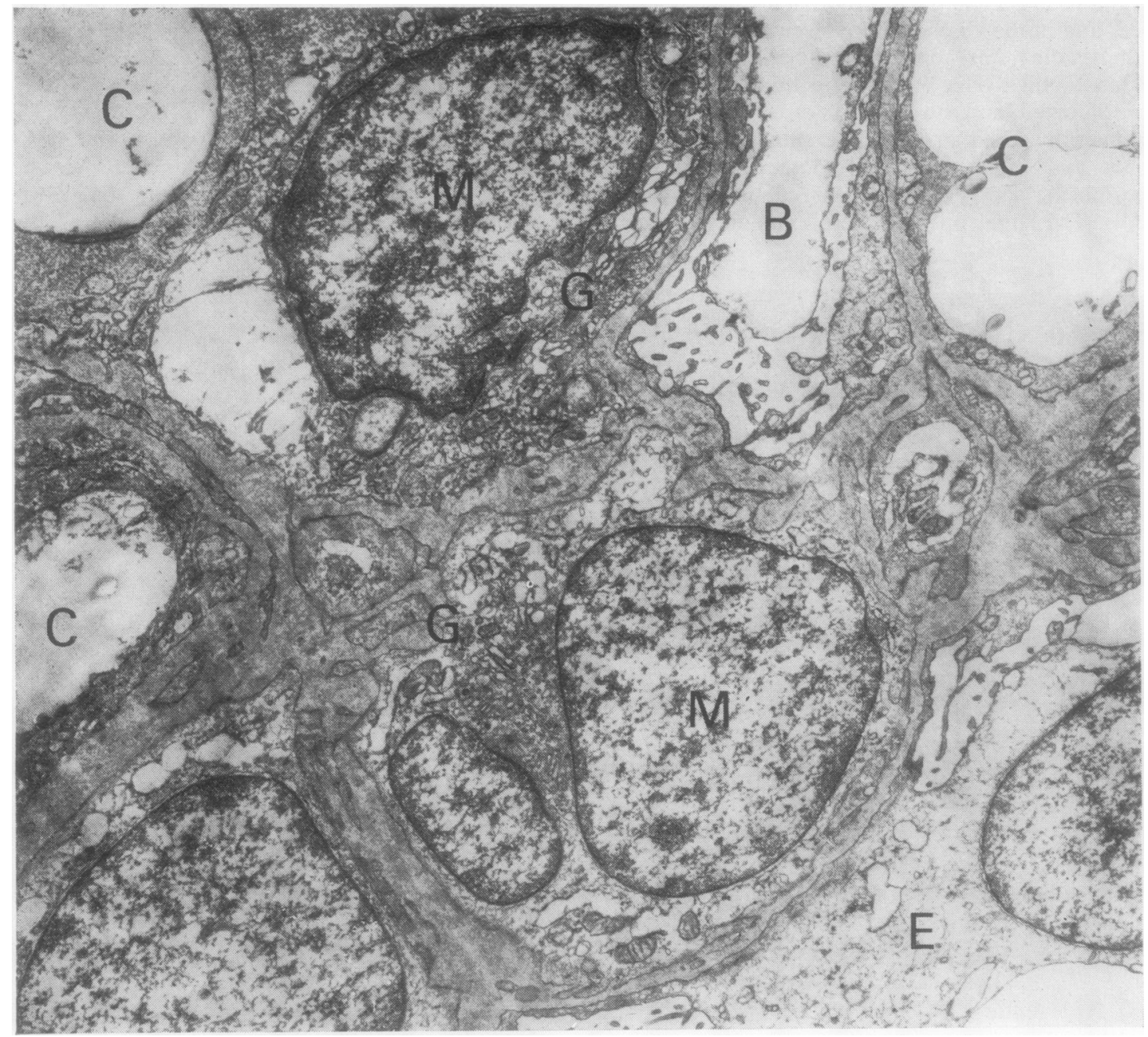

Fig. 5 Mesangial cells with irregular basement membranes. The endoplasmic reticulum is dilated and the Golgi apparatus prominent. Epithelial foot processes are fused. $\times 8,000 . \quad C=$ capillary $B M=$ basement membrane $B=$ Bowman's space $C B=$ complex body $E=$ epithelial cell $E n=$ endothelial cell $M=$ mesangial cell $F=$ fibrils $(B M$ and $N) \quad G=$ Golgi apparatus $\quad V=$ vesicles $\quad S=$ strands $(E)$ 
of urine. The serum cholesterol level had risen to $366 \mathrm{mg} / 100 \mathrm{ml}$. When he was transferred to the Royal Belfast Hospital for Sick Children on 19 March the ESR was $55 \mathrm{~mm}$ per hour, urea 39 $\mathrm{mg} / 100 \mathrm{ml}$, and protein electrophoresis showed IgG $110 \mathrm{mg} / 100 \mathrm{ml}$, IgA $90 \mathrm{mg} / 100 \mathrm{ml}$, and IgM $98 \mathrm{mg} / 100 \mathrm{ml}$. Renal biopsy was performed on 3 April and a diagnosis of focal glomerulonephritis was suggested. His general condition remained very poor and he was started on cyclophosphamide, $10 \mathrm{mg}$ daily, increasing to $20 \mathrm{mg}$ daily, without any improvement. He was also given salt-free globulin infusions, but continued on a downhill course until his death at 6 months of age on 20 July 1968.

LIGHT MICROSCOPY OF BIOPSY NO. 2673/68 This renal biopsy contained more than 30 glomeruli for examination. No very obvious lesion was seen apart from a slight patchy tubular dilatation involving convoluted tubules. Careful examination of the glomeruli revealed a focal proliferation of intercapillary cells in a few glomeruli (Fig. 3 ) and vacuoles

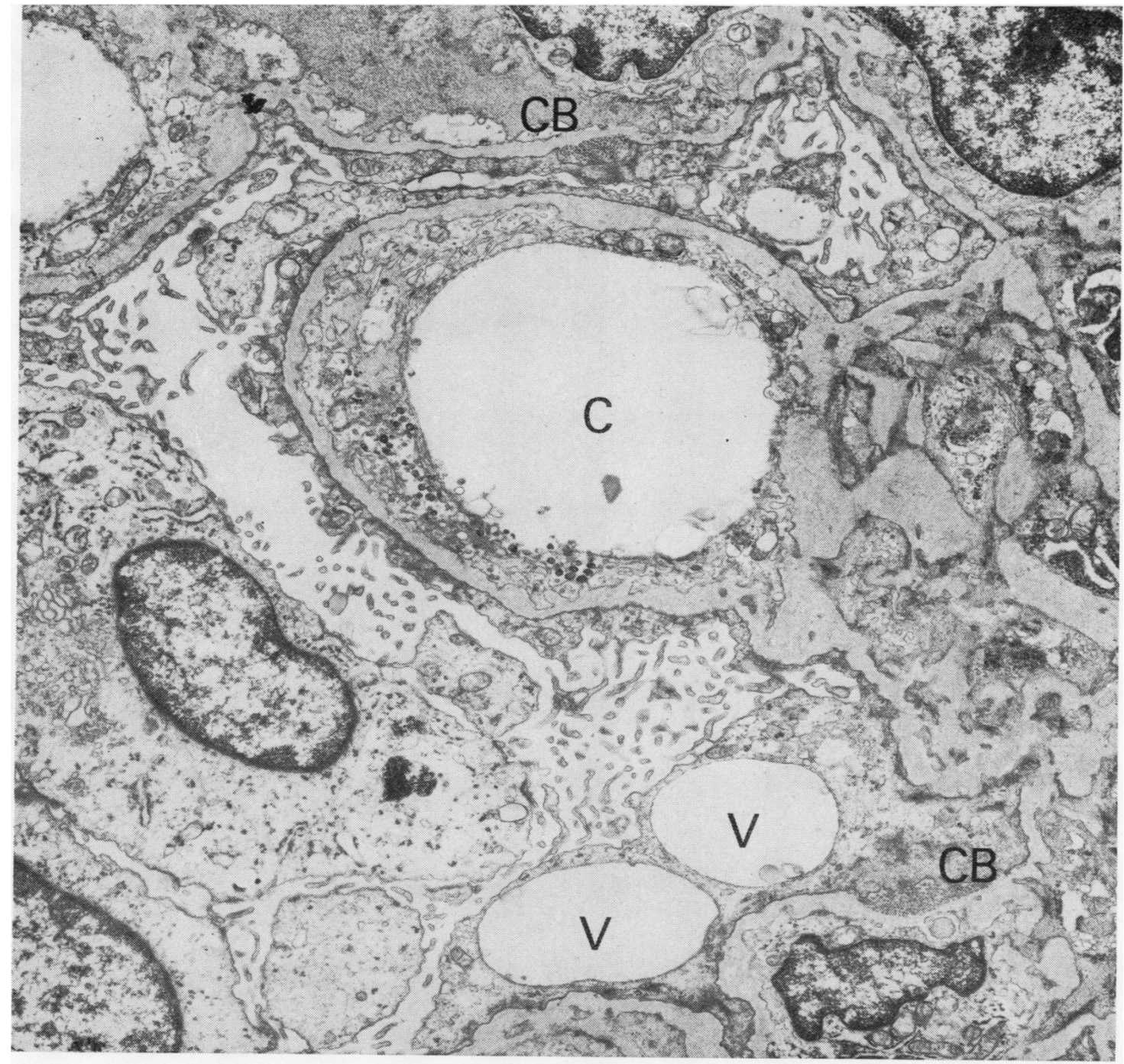

Fig. 6 A capillary loop shows almost complete epithelial foot-process loss. Vacuoles are prominent in the epithelial cells. There is marked irregularity of the basement membrane, especially on the endothelial side and over the mesangial cells. Complex bodies are present. $\times 8,000$. 
were observed in epithelial cells. There was no significant thickening of capillary basement membranes seen with PAS or silver methenamine stains. Some glomeruli demonstrated a fairly prominent superficial layer of cuboidal epithelium suggesting immaturity (Fig. 4). Fibrin thrombus was demonstrated in a capillary loop by PTAH staining. There was no increase in interstitial fibrous tissue or inflammatory cells. Small arteries appeared hyperplastic.
A diagnosis of focal glomerulonephritis was suggested.

NECROPSY FINDINGS

This infant was obviously emaciated with a protuberant abdomen. Straw-coloured fluid was present in each pleural cavity and there was free fluid and fibrino-purulent material in the peritoneal cavity. The main findings were in the kidneys and intestinal

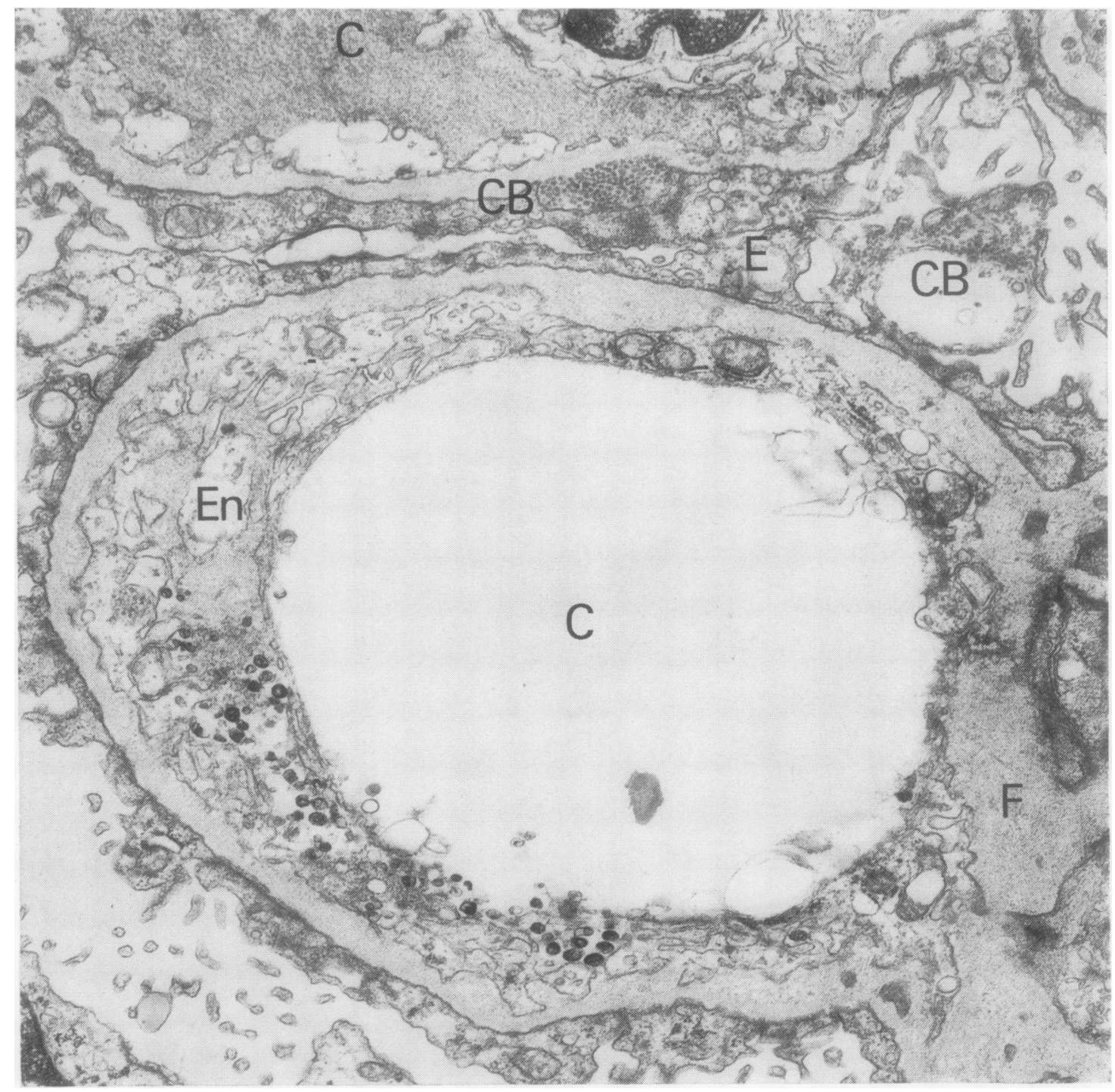

Fig. 7 Irregular prolongations of the capillary basement membrane extend into the endothelial cell cytoplasm.

Several dense bodies (? degeneration products) lie in the endothelium. The subepithelial complex body appears to lie within the basement membrane whilst another appears to be in the epithelial cell cytoplasm. The basement membrane over the mesangium has a fibrillar appearance. $\times 16,000$. 
tract. The latter showed marked dilatation and contained yellowish fluid. The loops of intestine were adherent to one another with a fibrino-purulent exudate on the serosa. The kidneys weighed $30 \mathrm{~g}$ each and the surfaces showed foetal lobulation. There were yellowish streaks in the cortices, which were generally pale. No cysts were seen and there was no obvious dilatation or inflammation in the pelvis. The renal vessels contained no thrombi.
Histological examination of the kidneys revealed isolated, mildly dilated tubules which appeared to be predominantly localized to the proximal region of the distal convoluted tubule at the region of the macula densa, directly related to glomeruli. No cyst formation was seen. The glomeruli generally appeared to fill Bowman's space, apart from a few which were superficial and appeared compressed, with dilatation of Bowman's space. As in the biopsy,

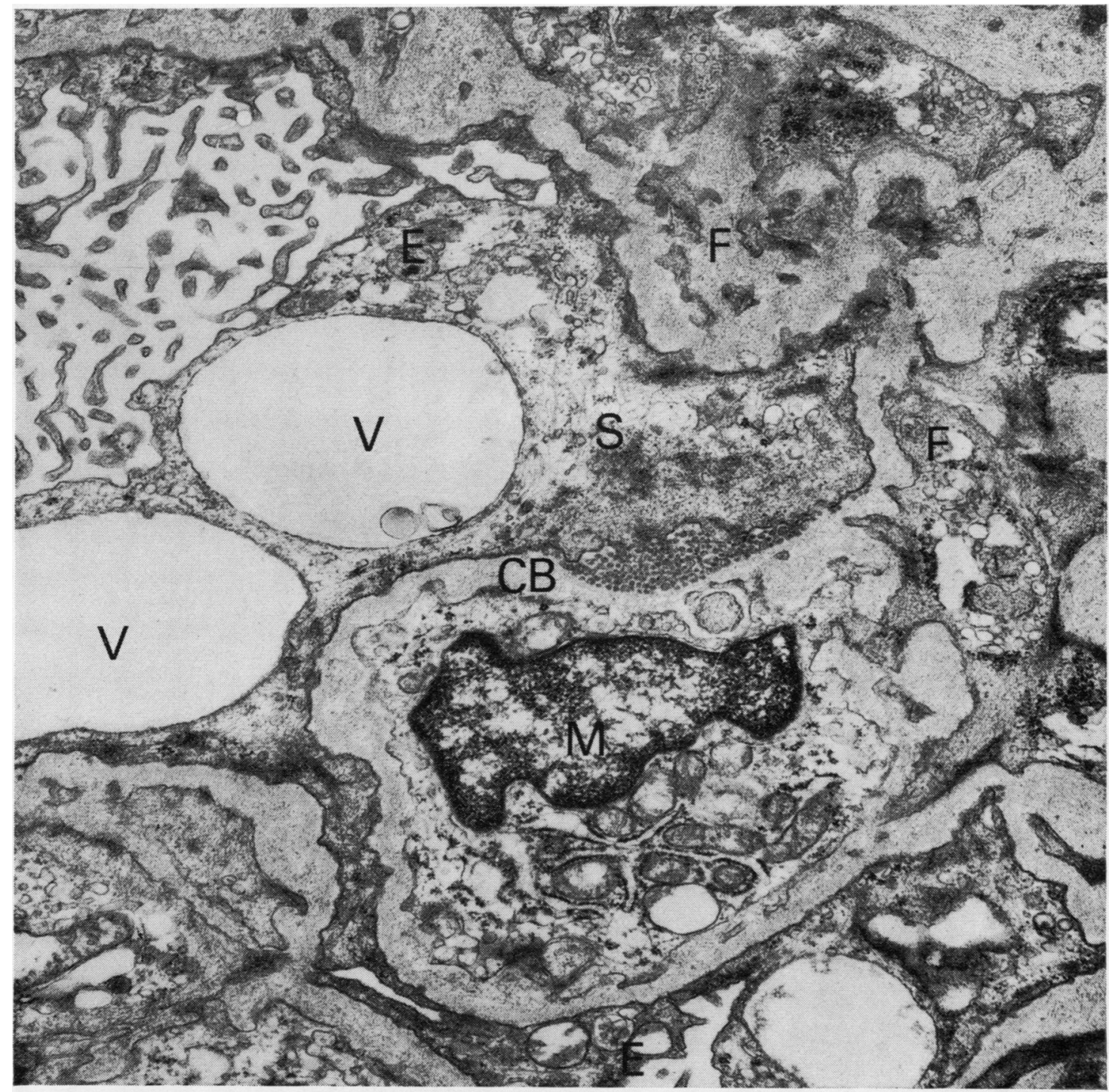

Fig. 8 A complex body extends along the basement membrane overlying the mesangium and is indistinctly separated from the overlying epithelium which contains dense granular material and fine, widely separated strands. The fibrillar/granular basement membrane merges with similar denser material in the mesangium. Rough endoplasmic reticulum is very prominent in a mesangial cell. $\times 16,000$. 
a few glomeruli showed focal proliferation of intercapillary cells and an occasional epithelial crescent was seen, with periglomerular fibrosis. No thickening of the capillary basement membrane was noted. Silver methenamine stains suggested collections of fibrillary silver-positive material in the axial areas. Two microscopic areas of dysplastic tubules and surrounding condensed mesenchyme were seen but there was no general increase in fibrous tissue and no inflammatory infiltrate. Proteinaceous casts were present in some tubules.
ELECTRON MICROSCOPY EM $59 / 68$

Portions of renal biopsy tissue were fixed immediately in buffered osmium tetroxide, embedded in epon, and examined using an AEI EM6 electron microscope (Figs. 5-9). This confirmed the increase in intercapillary cells and basement membrane-like material, particularly in the mesangial region. Here the basement membranes varied greatly in width, appeared fibrillar or granular (Fig. 7), and in certain areas tended to fuse with the underlying mesangial cell cytoplasm which also showed varying degrees of

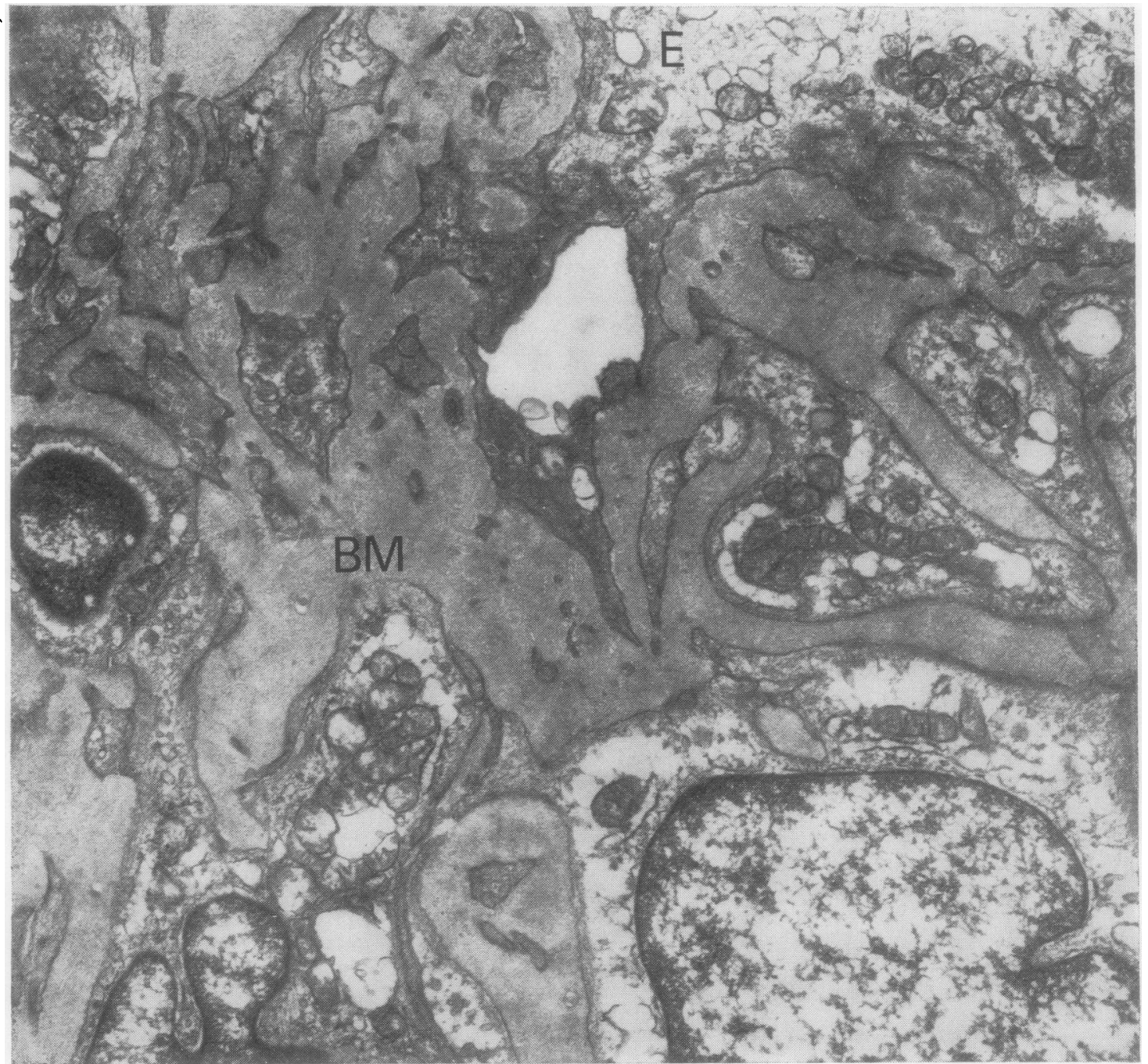

Fig. 9 The basement membrane is completely disorganized with numerous inclusions of cytoplasm and the electron density is very variable. The overlying epithelium shows marked increase in density immediately adjacent to the basement membrane. $\times 16,000$. 
fibril formation, generally of greater electron density than the basement membrane itself (Fig. 8). The irregularity in thickness of peripheral capillary basement membrane was less marked but still present, prolonged inwards, and sometimes fading into continuity with the endothelial cell cytoplasm (Figs. 6, 7). Rarely small collections of regularly arranged rounded bodies were noted within the basement membrane, lying in a subepithelial position and generally, but not always, definitely separated from the overlying epithelial cell (Figs. 7, 8). One small area of similarly arranged bodies was noted in an epithelial cell (Fig. 7), though this might be due to tangentially cut basement membrane. The appearances of each of these structures suggested unusual antigen-antibody complexes. Epithelial foot processes were almost always fused to form a continuous sheet of cytoplasm over the basement membrane (Figs. 5-9). Vacuoles were often prominent within the epithelial cells and occasionally the Golgi apparatus and rough endoplasmic reticulum were pronounced (Fig. 6). Immediately adjacent to the basement membrane the epithelial cell cytoplasm showed increased electron density (Fig. 9). The possibility of fibril formation within the cytoplasm by the side of a large vacuole was observed in one glomerulus. There were a few inclusions of endothelial or epithelial cytoplasm within the basement membrane and considerable variations in density were observed. No subendothelial inclusions were encountered and there was no observed proliferation of endothelial cells. Apart from showing a numerical increase, the mesangial cells often contained prominent Golgi bodies and abundant rough endoplasmic reticulum with ribosomes (Fig. 8).

\section{Case 3 (C.C. A25162)}

This infant was delivered on 3 November 1967 weighing $2,727 \mathrm{~g}$. No details about the placenta are available. On 17 November she was admitted to hospital with cellulitis and oedema of the lower abdominal wall. On examination she was very small and pale, weight $2,545 \mathrm{~g}$, temperature $35.5^{\circ} \mathrm{C}$. The lower half of the abdomen was red and pitting oedema was present in the perineum and upper thighs. Oedema of the eyelids was also noted. There was no discharge from the umbilicus. A skin swab grew Staph. aureus, coagulase positive, sensitive to all antibiotics. Haemoglobin was $13.4 \mathrm{~g} / 100 \mathrm{ml}$ (Haldane). The urine contained protein ++++ and a trace of sugar. Urine culture on 22 November grew coliforms resistant to sulphonamide and sensitive to Furadantin. She was transferred to the Royal Belfast Hospital for Sick Children on 23 November with severe generalized oedema and there was shifting dullness of the abdomen. The total plasma proteins were $2 \cdot 8 \mathrm{~g} / 100 \mathrm{ml}$ (albumin $0.7 \mathrm{~g} / 100 \mathrm{ml}, \alpha_{2}$ globulin $1.2 \mathrm{~g} / 100 \mathrm{ml}, \gamma$ globulin $0.3 \mathrm{~g} / 100 \mathrm{ml}$ ). A presumptive diagnosis of the nephrotic syndrome was made and she was given diuretics and a high-protein diet. Her condition deteriorated steadily. The blood urea rose to 195 $\mathrm{mg} / 100 \mathrm{ml}$ and the cholesterol level to $385 \mathrm{mg} / 100 \mathrm{ml}$ five days before death. Immunoglobulins were reported as IgG $6.0 \mathrm{mg} / 100 \mathrm{ml}, \operatorname{IgA} 21.0 \mathrm{mg} / 100 \mathrm{ml}$, IgM $135 \mathrm{mg} / 100 \mathrm{ml}$, and an amino-acid chromatogram done on 27 November was later reported as showing, after deproteinization, a gross generalized aminoaciduria.

The baby had only one sibling, an older brother born on 29 May 1966, who was alive and well. There was no consanguinity and none of the paternal or maternal kinships had any history of renal disease.

\section{NECROPSY FINDINGS}

This severely oedematous infant weighed $2,250 \mathrm{~g}$, and all body cavities contained excess strawcoloured fluid. The kidneys weighed $28 \mathrm{~g}$ each and after stripping the capsules with ease the surfaces showed marked foetal lobulation. Both kidneys were pale, especially the cortices. No gross lesion was evident on cut section and there was no inflammation of the pelves (Fig. 10). Thrombus could not be detected in the renal vessels. The spleen was small and firm, weighing $5 \mathrm{~g}$. The thymus weighed $3 \mathrm{~g}$ and appeared atrophic. The uterus was bicornuate. No other lesion was seen.

Histological abnormalities were observed in the liver, spleen, kidneys, thymus, and lymph nodes, with incomplete neuronal and neuroglial migration in the cerebral cortex and a cellular molecular layer and incomplete migration in the granular layer of the cerebellar cortex suggesting immaturity of approximately 35 to 40 weeks' gestation. The liver showed focal necrosis and fibrin precipitation in sinusoids. The splenic pattern was completely disrupted by numerous fine and thick bands of fibrous tissue, dividing it into lobules of varying size. The appearances suggested a congenital anomaly with possible aggregation of numerous spleniculi around a vascular pedicle. The thymus was extremely atrophic in appearance with numerous large Hassall's corpuscles, a few surrounding lymphocytes, and medullary or epithelioid cells. General cortical lymphoid depletion was seen in the lymph nodes.

The most striking histological feature of the kidneys on superficial examination was the tubular dilatation and proteinaceous casts. The epithelial cells varied from flattened to swollen, pale, and granular. No necrosis was seen (Fig. 11). The tubular 


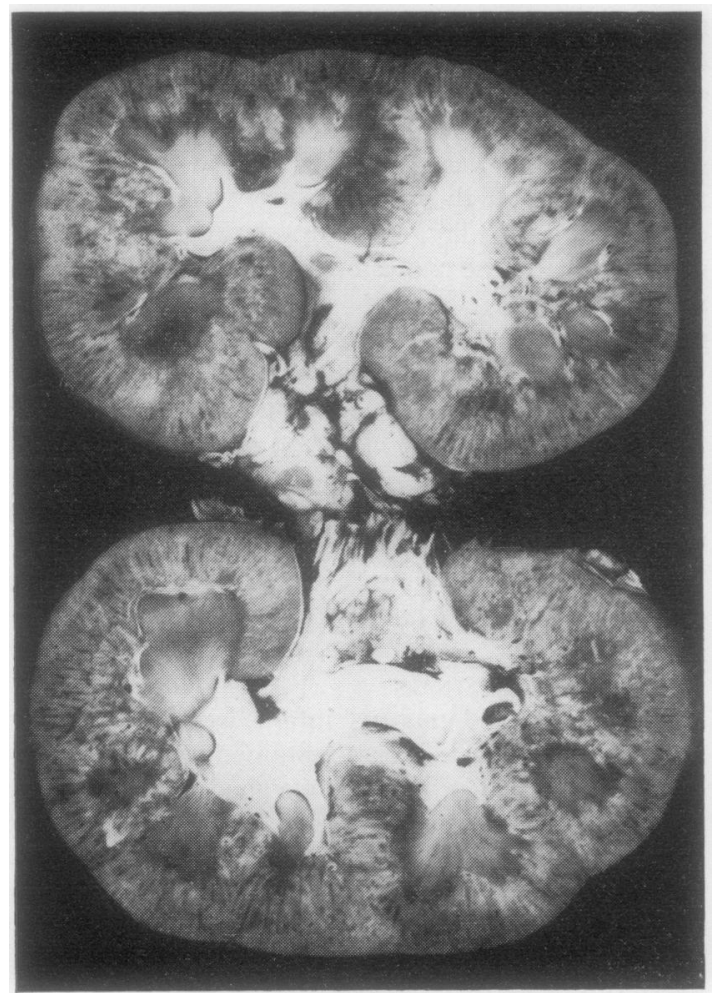

Fig. 10 The posterior half of each kidney shows only increased thickness of the cortex.

dilatation was not confined to the convoluted tubules but extended to the collecting tubules in the medulla. There were red cell casts in occasional tubules. Glomeruli on first impression appeared reduced in number, but it was difficult to be certain of this and no normal glomeruli were seen. Some were shrunken and Bowman's space was dilated. Others filled Bowman's space. Immature glomeruli with a prominent superficial layer of cuboidal epithelium were present and in many other glomeruli capillary channels were located only with difficulty. In some of the larger juxtamedullary glomeruli one or two dilated capillary channels were accompanied by a sheet-like area of cells and basement-membranelike material. An occasional epithelial crescent was seen and there were adhesions between tuft and Bowman's capsule. There was little increase in interstitial fibrous tissue and no significant inflammatory cell infiltrate. The small arteries appeared hyperplastic. No inflammation was seen in the pelvis. One branch of a renal vein contained an organized calcified thrombus.

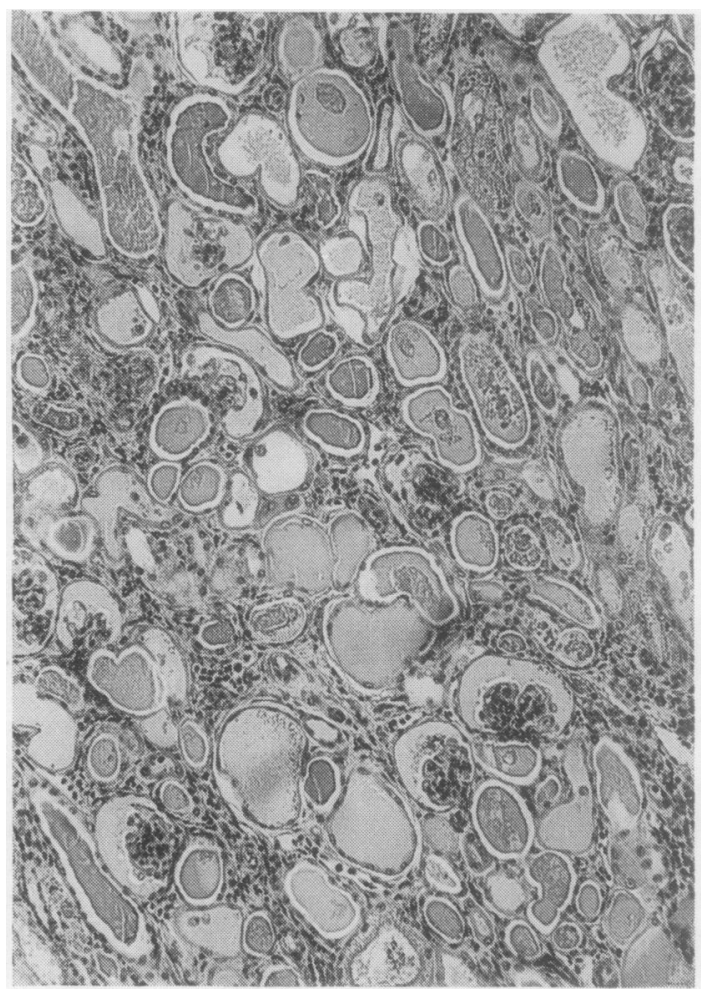

Fig. 11 Generalized tubular dilatation and proteinaceous cast formation in case 3. $H$ and $E \times 100$.

\section{ELECTRON MICROSCOPY}

The findings closely resembled those previously described in case 2 and will not be repeated. Myelin figures were noted occasionally. Marked variations were observed in tubular epithelial cells, but absorbed protein droplets were numerous. Irregularities in the tubular basement membranes were common.

\section{Case 4 (J.R. A20401)}

This white male infant aged 11 days was admitted to the Johns Hopkins Hospital on 25 September 1946 because of colonic convulsions of intermittent nature for the preceding four days. He had been born at home; delivery at full term was uncomplicated and he cried immediately. He weighed $2,545 \mathrm{~g}$. For the first week he fed normally and then had what was apparently a typical convulsion. He was sleepy afterwards and over the next four days had approximately 20 similar episodes daily. The mother noticed that the baby's feet were swollen on the day of the 
first convulsion. The family history was negative. Physical examination revealed oedema of the legs, penis, scrotum, and abdominal wall, with mottling of the lower extremities. The only other findings were a full fontanelle, intermittent cyanosis of the feet, hands, and perioral areas, and venous patterns over the upper abdomen.

The weight on admission was $3,272 \mathrm{~g}$. Laboratory investigations revealed the following. The haemoglobin was $19 \mathrm{~g} / 100 \mathrm{ml}$, WCC 16,250/c mm. Urine examination showed albumin ++ . Serum $\mathrm{Ca}$ was $5.47 \mathrm{mg} / 100 \mathrm{ml}, \mathrm{P} 6.82 \mathrm{mg} / 100 \mathrm{ml}$, albumin $2.42 \mathrm{~g} /$ $100 \mathrm{ml}$, globulin $1.03 \mathrm{~g} / 100 \mathrm{ml}$, and cholesterol and urea were normal.

Treatment with intravenous plasma and $\mathrm{Ca} \mathrm{Cl}_{2}$ was started and the convulsions ceased. A 24-hour urine specimen on 3 October showed $6.0 \mathrm{~g}$ protein/ litre, albumin $4.88 \mathrm{~g}$, and globulin $1.17 \mathrm{~g}$. On 5 October the serum cholesterol was $358 \mathrm{mg} / 100 \mathrm{ml}$. There was a decreasing albumin/globulin ratio, lipid casts in the urine, and raised ESR. Urine and throat cultures remained negative. By 17 October urine culture grew $B$. coli. Granular casts, 3-5 red cells, and 20-30 white cells/high-power field were seen in the urine and treated with sulphonamides. The serum cholesterol level rose to 448 $\mathrm{mg} / 100 \mathrm{ml}$. Serum electrophoresis showed a typical nephrotic pattern and he developed episodes of heart failure treated by digitalis. The oedema of the lower limbs subsided, but parecantesis had to be carried out on several occasions for ascites. He deteriorated fairly rapidly and died on 31 January 1947.

\section{NECROPSY FINDINGS}

The infant weighed $3,500 \mathrm{~g}$. The abdomen was markedly protuberant and tense with prominent superficial distended veins extending up from the inferior epigastric region to the costal margins on both sides. No peripheral pitting oedema was present. The pleural cavities contained no excess of free fluid, the peritoneal cavity about $5 \mathrm{ml}$ of cloudy, yellowish fluid. Organizing thrombus was found in the left main pulmonary artery, apparently occluding its lumen, and small thrombi were present in the vessels of the left lung. No infarcts were seen. The left kidney weighed $30 \mathrm{~g}$, the right $35 \mathrm{~g}$. Foetal lobulation was prominent and the capsules stripped easily to reveal smooth surfaces. The left renal vein was completely occluded by thrombus while nonocclusive thrombus was also seen in the right renal vein. The cut surface of the kidneys revealed a fine granularity of the cortex with a yellowish colour suggesting the presence of fat. The width of the cortex was 4-5 $\mathrm{mm}$ and the cortico-medullary junction was distinct.
The inferior vena cava was completely occluded by organizing thrombus from the intrahepatic portion of the iliac veins on both sides, the thrombus also extending into the renal veins and hepatic veins. Considerable retroperitoneal fibrosis was evident around the vena cava and aorta, extending around the kidneys and adrenals and into the lumbar and pelvic regions. No evidence of active intraperitoneal infection was found. Thickening of the costochondral junctions suggested rickets. No intracerebral lesion was seen, but subarachnoid haemorrhage was present in the right parietal region.

The significant microscopic findings were recanalized and organizing thrombus occluding the lumen of the inferior vena cava and both main renal veins. Organizing thrombus partly occluded a pulmonary artery. The kidneys showed remarkably little pathology apart from very prominent dilatation of capsular vessels and also those at the corticomedullary junction, in the pelvis, and in the perirenal tissue. Immature glomeruli were scattered throughout the sections. There was no suggestion of increased glomerular cellularity and no crescent formation, no adhesion of tuft to Bowman's capsule, and rarely periglomerular fibrosis. Capillary basement membranes were not visibly thickened. Tubular dilatation was not prominent and the tubular epithelium was only slightly granular in appearance.

\section{Discussion}

As often happens with relatively rare and new diseases, a great diversity in nomenclature may occur. The most popular designation is 'congenital nephrotic syndrome', which in no way alludes to a possible aetiology. This title is very popular in Finland where most cases have been discovered so far. Inherent within this title, however, is the existence of the features of the nephrotic syndrome at birth and this is not always the case, the onset of clinical features being as late as the fourth month of life in rare cases.

These infants are often born prematurely and are of low birth weight, with wide separation of the skull bones indicating immature bony development. Contrary to the foetal size the placenta is generally markedly enlarged. The normal foetal-placenta ratio is approximately $6: 1$ to $8: 1$, but in the series of 17 cases studied by Kouvalainen et al (1962) the ratio was altered to $0 \cdot 9: 1$ to $4: 1$ and in two of them the placenta was $300 \mathrm{~g}$ heavier than the infant. Typically the placenta is grossly oedematous with cotyledons of varying size. Histology reveals the features described in case 1 and there are obvious similarities between this placenta and that of erythroblastosis. 
It is interesting to speculate that some cases of hydrops, not associated with detectable blood incompatibility, may be cases of the congenital nephrotic syndrome.

Soon after birth cyanosis may be seen, especially when feeding, and there may be respiratory difficulties or abnormal crying-usually a high pitched squeal.

The cardinal presenting feature, as in the nephrotic syndrome of older children and adults, is oedema, very marked and usually present in congenitally nephrotic infants at birth or during the first few weeks of life. Norio (1966) pointed out that of 71 cases, $52 \%$ had oedema and proteinuria during the first week of life, $94 \%$ during the first eight weeks, and the remaining $6 \%$ not later than the fourth month. The nephrotic syndrome of childhood, which usually has a much more benign outcome, rarely occurs before 1 year of age. There is, therefore, a natural gap in the development of the nephrotic syndrome from 4 months to 1 year.

The laboratory data are, as in the nephrotic syndrome of any age group with proteinuria, hypoalbuminaemia, raised $\alpha_{2}$-lipoprotein levels, and progressive hypercholesterolaemia. The elevation of IgM, if present, is characteristic of the congenital nephrotic syndrome. Azotaemia generally occurs late in the disease and the infants are very susceptible to infection, especially $E$. coli. Steroid therapy and immunosuppressants when used have proved useless. Death, often from infection, occurs within a few weeks or months and rarely later than one year, though one infant survived for three years and 10 months.

From this discussion of the clinical features of the congenital nephrotic syndrome, it would appear that the cases 1 and 2 fall fairly easily into the appropriate pattern, being familial and having enlarged placentae, the foetal-placental ratio for case 2 being 1.6:1 and the placenta from case 1 , though not all available for study, being considered 'massive' and showing appropriate histological features. Each had early cyanosis and oedema was evident at 1 month and 8 days respectively. The typical clinical course and laboratory data were observed, the IgA and IgM being raised. Death occurred at 9 weeks and 6 months respectively, despite steroid therapy and also cyclophosphamide in the latter (for normal immunoglobulin values in infants see Stiehm and Fudenberg, 1966).

The absence of a family history and the lack of data concerning the placenta of case 3 do not exclude it from a diagnosis of congenital nephrotic syndrome of similar aetiology since the typical clinical features were observed at age 2 weeks, and the markedly raised $I g A$ of $21 \mathrm{mg} / 100 \mathrm{ml}$ and $I_{g} M$ of
$135 \mathrm{mg} / 100 \mathrm{ml}$, supposedly characteristic of this disease, were obtained. The clinical progress was also typical, with death at 1 month due to infection and uraemia. There were, however, unusual features such as the finding of generalized aminoaciduria which was also noted in case 1 .

The histological features of the kidneys in cases 1 and 2, with immature superficial glomeruli, focal proliferation of intercapillary cells and epithelial cells with crescent formation, adhesions of the glomerular tufts of Bowman's capsule, with mild patchy tubular dilatation, are those typically described in this syndrome.

The marked cystic dilatation of tubules accompanying the glomerular lesions in case 3 bears a striking resemblance to those found in a nephrotic infant by Hallman, Hjelt, Eklund, and Paatela (1962). They attributed the clinical findings to the tubular dilatation and agreed with Oliver (1960) who believed that certain cases of infantile nephrosis could be descriptively designated as 'infantile microcystic renal disease'. In the absence of a family history Hallman et al (1962) did not consider their case as a true example of the familial form of the congenital nephrotic syndrome. However, similar histological findings have been reported in siblings with the nephrotic syndrome (Giles et al, 1957). The present case under discussion is unusual in that other congenital abnormalities were present. This may have been incidental or the renal and other abnormalities may have been on the basis of viral infection or other insult during foetal life, the laboratory findings, as suggested earlier, supporting an immunological upset. The haphazard cystic appearance of the tubules is consicered secondary to the massive protein content of the glomerular filtrate with obstruction of the tubules and secondary dilatation. It seems unlikely that such proteinuria could be explained on the basis of tubular loss alone and the glomerular lesions secondary to intrarenal hydronephrosis.

Foot process loss and basement membrane thickening with irregularity of the endothelialbasement membrane junction have been reported previously (Worthen, Vernier, and Good, 1959; Parker and Piel, 1960). The degree of basement membrane thickening seen here is extremely marked and variable and of uneven density. In some areas the epithelial cells show increased electron density immediately adjacent to the basement membrane and an increase in mesangial cells is seen. The nephrotic syndrome in older children and adults is associated with a variety of glomerular lesions. The combination of basement membrane changes and cellular proliferation, predominantly of the intercapillary or mesangial variety, but occasionally 
epithelial with crescents visible on light microscopy, suggest a mixed pattern, though the epithelial element may well be related to a superimposed lesion such as fibrin formation. It is also possible that developing glomeruli may react differently from mature glomeruli to any given stimulus and that the range of lesions seen may be a manifestation of the stage of maturity of the glomeruli at the time of insult. The variation in glomerular alteration from superficial to deep cortex lends weight to this possibility. Whilst the lesion, as visualized clinically and by light (case 1), electron (cases 2 and 3), and fluorescent microscopy (Lange, Wachstein, Wasserman, Alptekin, and Slobody, 1963), best ties in with a glomerulonephritic lesion in the present state of our knowledge, we must also consider the possibility of an inborn error of protein synthesis with a defect in basement membrane production as suggested by Hallman, Norio, and Kouvalainen (1967). The very unusual findings in the basement membrane described may represent a formation defect. Irrespective of aetiology it is obvious that the initiation of the renal lesion must occur during foetal life to produce hypoproteinaemic oedema at or soon after birth. If we consider the congenital nephrotic syndrome to be a glomerulonephritic lesion then an antigen-antibody reaction must take place either in the blood stream, with localization in the basement membrane, or the antibodies must be directed against renal tissue or react with it. Lange et al (1963) have suggested that the antibody formation occurs in the mother. Immunological incompatibility between mother and infant born with this syndrome is suggested by the 'second set' reaction observed by Kouvalainen et al (1962) following the transplantation of skin from the nephrotic infant to the mother.

Antigenicity of the placenta has been disputed by many workers, but the existence of a renal-placental relationship was suggested as early as 1886 by Fehling and by Wiedow in 1888 , and the possible significance of this to the development of eclampsia was mentioned as early as the turn of the century by Veit (1902). The nephrotoxicity of antiplacenta serum has been demonstrated by Seegal and Loeb (1946) and McCaughey (1955) and the antigenic relationships between placenta and kidney in humans have been elucidated by Boss (1965). Four groups of common antigens were identified. Antigens of the mitochondrial and microsomal fractions were present in the cytoplasm of the placental trophoblast and renal proximal tubular epithelium; microsomal antigens occurred in the visceral glomerular epithelium and antigens of the heavy particle fraction resided within the epithelial and mesenchymal basement membranes. He was unable to demonstrate any circulating antibodies in the serum of normal or toxaemic patients. More recently Levanon and Rossetini (1968) demonstrated placental antigen, which may be found in the circulation of normal gravidas, and also an antibody of this antigen, detectable in toxaemic patients and in normal puerperal women. From these findings one may suggest that under certain circumstances antibodies may be formed by the mother against placental antigen in the circulation. Is it not possible then that antibody formed in the mother may pass to the foetus and there react with glomerular and/or renal tubular fractions cross-reacting with placenta? Antigen-antibody complexes may, by alteration of the glomerular capillary basement membrane, allow transient passage of cross-reacting antibody to come in contact with some tubular component, with release into the foetal circulation of autologous antigenic substances. Such a mechanism has been suggested by Barabas and Lannigan (1969) as providing a continuous source of renal antigen in autoimmune nephritis in rats. This experimental model bears the closest morphological and clinical resemblance to membranous glomerulonephritis in man, a variety of nephritis associated with the nephrotic syndrome.

The finding of an abnormal placenta in the congenital nephrotic syndrome adds weight to the possibility that it is implicated in the disease process, though the oedematous villi may be merely a manifestation of the easier passage of fluid in hypoproteinaemia into the very loose mesenchymal tissue and a sign of a similar though less easily recognizable accumulation of fluid in other foetal tissues.

Attempts to produce the congenital nephrotic syndrome experimentally have been rare and unsuccessful (Hallman, Hjelt, and Kouvalainen, 1960). The effects of nephrotoxic serum and aminonucleoside of puromycin administered to pregnant rats have been studied, but the electron microscopy and clinical findings in patients with this syndrome suggest that the foetal kidney should be studied after the administration of antiplacenta serum which may produce a lesion similar to the Heymann type autoimmune nephritis in rats.

Renal vein thrombosis was observed in three of these infants. Thrombosis of the renal veins was first described by Rayer (1840), but only comparatively recently has great interest been shown in this condition. It is well recognized now that occlusion of the renal veins is often, though not invariably, associated with the nephrotic syndrome in adults (Pollack, Kark, Pirani, Shafter, and Muehrcke, 1956). In infants, however, renal vein thrombosis, which is usually associated with states of dehydration or sepsis, is almost invariably 
manifested pathologically by haemorrhagic infarction. Torres (1962) considered his case as primary renal vein thrombosis with a secondary nephrotic syndrome. His only comment on the glomeruli was that they were unremarkable. Fetterman and Feldman (1960), as previously indicated, believed that the primary lesion in their case was a proximal tubular abnormality with secondary occlusion of the right renal vein. Roy et al (1964) suggested that possibly the alteration in serum lipid concentration observed in the nephrotic syndrome could trigger a thrombotic accident. In our present cases no acute symptoms of renal vein or inferior vena cava thrombosis were detected and the very limited degree of thrombosis in case 3 strongly suggests a secondary role. In cases 1 and 4, however, bilateral renal vein thrombosis was observed, with involvement of the inferior vena cava also in case 4 . Under these circumstances, one can but draw on the clinical and pathological features of the individual case to determine cause and consequence. The clinical features in case 4 suggest primary vena caval and renal vein thrombosis and this is at least partly substantiated by the absence of morphological lesions in the kidneys, relative to those observed in the other three cases. The very extensive thrombosis noted at necropsy and the retroperitoneal fibrosis around the vena cava, aorta, kidneys, and adrenals may well be associated, and possibly both are related to, healed retroperitoneal inflammation or trauma. The most likely relationship, therefore, in this patient is primary renal vein thrombosis with secondary nephrotic syndrome indicating the probable multiple aetiology of this syndrome, even in infants. In case 1 , the family history, the placental abnormality, the typical clinical findings, and pathological changes in the kidneys weigh heavily in favour of a primary renal lesion with secondary renal vein thrombosis.

Our thanks are due to Dr R. H. Heptinstall, Director, Department of Pathology, to the Johns Hopkins Hospital for permission to publish case 4 , to $\mathrm{Dr}$ J. E. Morrison for the sections of placental tissue and his assistance in their histological interpretation, and to Professor Sir John Biggart, CBE, Professor E. F. McKeown, and Professor R. Lannigan for advice during this study.

\section{References}

Barabas, A. Z., and Lannigan R. (1969). Auto-immune nephritis in rats. J. Path., 97, 537-543.
Boss, J. H. (1965). Antigenic relationships between placenta and kidney in humans. Amer. J. Obstet. Gynec., 93, 574-582.

Fehling, H. (1886). Ueber habituelles Absterben der Frucht bei Nierenerkrankung der Mutter. Arch. Gynaek., 27, 300-306. Quoted by Boss, J. H. (1965).

Feinerman, B., Burke, E. C., and Bahn, R. C. (1957). The nephrotic syndrome associated with renal vein thrombosis. J. Pediat., Dis. 51, 385-391.

Fetterman, G. H., and Feldman, J. D. (1960). Congenital anomalies of renal $t$ ubules in a case of "infantile nephrosis". Amer. J. Dis. Child., 100, 319-332.

Giles, H. McC., Pugh, R. C. B., Darmady, E. M., Stranack, F., and Woolf, L. I. (1957). The nephrotic syndrome in early infancy: a report of three cases. Arch. Dis. Childh., 32, 167-180.

Hallman, N., Hjelt, L., and Kouvalainen, K. (1960). Attempts to produce experimental congenital nephrosis. A preliminary report. Ann. paediat. Fenn., 6, 289-298.

Hallman, N., Hjelt, L., Eklund, J., and Paatela, M. (1962). Microcystic disease simulating congenital nephrotic syndrome. Ann. paediat. (Basel), 199, 493-501.

Hallman, N., Norio, R., and Kouvalainen, K. (1967). Main features of the congenital nephrotic syndrome. Acta paediat. scand., suppl., 172, 75-78.

Kendall-Smith, I. M., Pullon, D. H. H., and Tomlinson, B. E. (1968) Congenital nephrotic syndrome in Maori siblings. N.Z. med.J. 68, $156-160$.

Kouvalainen, K., Hjelt, L., and Hallman, N. (1962). Placenta in congenital nephrotic syndrome. Ann. paediat. Fenn., 8, 181-188.

Lange, K., Wachstein, M., Wasserman, E., Alptekin, F., and Slobody, L. B. (1963). The congenital nephrotic syndrome: an immune reaction? Amer. J. Dis. Child., 105, 338-345.

Levanon, Y., and Rossetini, S. M. O. (1968). Presence of circulating placental antigens and antibodies in toxemic and normal pregnancy patients. $Z$. Immun.-Forsch., 136, 178-186.

McCaughey, W. T. E. (1955). The nephrotoxic action of anti-placenta serum in rats. J. Obstet. Gynaec. Brit. Emp., 62, 863-869.

Norio, R. (1966). Heredity in the congenital nephrotic syndrome. A genetic study of 57 Finnish families with a review of reported cases. Ann. paediat. Fenn. 12, (Suppl. 27) 1-94.

Oliver, J. (1960). Microcystic renal disease and its relation to "infantile nephrosis"'. Amer. J. Dis. Child., 100, 312-318.

Parker, R. A., and Piel, C. F. (1960). The nephrotic syndrome in the first year of life. Pediatrics, 25, 967-976.

Pollack, V. E., Kark, R. M., Pirani, C. L., Shafter, H. A., and Muehrcke, R. C. (1956). Renal vein thrombosis and the nephrotic syndrome. Amer. J. Med., 21, 496-520.

Rayer, P. F. O. (1840). Traité des maladies des Reins et des Alteration de la Secretion Urinaire, vol. 2, p. 590. J. B. Ballière. Paris

Roy, C. C. Bedard, G., Bonenfant, J. L., and Fortin, R. (1964) Congenital nephrosis associated with thrombosis of the inferior vena cava and of the right renal vein in a six week old premature infant. Canad. med. Ass. J., 90, 786-789.

Seegal, B. C., and Loeb, E. N. (1946). The production of chronic glomerulonephritis in rats by the injection of rabbit anti-ratplacenta serum. J. exp. Med., 84, 211-222.

Stiehm, E. R., and Fudenberg, H. H. (1966). Serum levels of immune globulins in health and disease: a survey. Pediatrics, 37, 715-727.

Torres, E. R. (1962). Nephrotic syndrome in an infant secondary to renal vein thrombosis. Harper Hosp. Bull., 20, 172-178.

Veit, J. (1902). Ueber Albuminurie in der Schwangerschaft: ein $\omega$ Beitrag zur Physiologie der Schwangerschaft. Berl.. Klin. Wschr., 39, 513-516. Quoted by Boss, J. H. (1965).

Wiedow, W. (1888). Ueber den Zusammenhang zwischen Albuminurie und Placentarerkrankung. Z. Geburtsh. Gynäk., 4, 387-404. Quoted by Boss, J. H. (1965).

Worthen, H. G., Vernier, R. L., and Good, R. A. (1959). Infantile nephrosis. Amer. J. Dis. Child., 98, 731-748. 